Editorial

\title{
Announcing the 2019 Processes Travel Awards for Post-Doctoral Fellows and Ph.D. Students
}

\author{
Michael A. Henson ${ }^{1}{ }^{*}$, Juergen Hahn ${ }^{2} \mathbb{D}$, Martha A. Grover ${ }^{3} \mathbb{D}$, John D. Hedengren ${ }^{4} \mathbb{D}$ and \\ Processes Editorial Office ${ }^{5}$ \\ 1 Department of Chemical Engineering and the Institute for Applied Life Sciences, University of \\ Massachusetts Amherst, N527 Life Sciences Laboratories, 240 Thatcher Way, Amherst, MA 01003, USA \\ 2 Department of Biomedical Engineering, Department of Chemical \& Biological Engineering, \\ Center for Biotechnology and Interdisciplinary Studies, Rensselaer Polytechnic Institute, \\ Troy, NY 12180, USA; hahnj@rpi.edu \\ 3 School of Chemical \& Biomolecular Engineering, Georgia Institute of Technology, 311 Ferst Dr. NW, \\ Atlanta, GA 30332-0100, USA; martha.grover@chbe.gatech.edu \\ 4 Department of Chemical Engineering, 350 CB, Brigham Young University, Provo, UT 84602, USA; \\ john_hedengren@byu.edu \\ 5 Suite 305, Zhongjia Mansion, Building No.13, Taiyangyuan Community, Dazhongsi East Road, \\ Haidian District, Beijing 100098, China; processes@mdpi.com \\ * Correspondence: mhenson@umass.edu; Tel.: +1-413-545-3481
}

Received: 29 December 2018; Accepted: 29 December 2018; Published: 3 January 2019

In order to support the development of early career researchers involved in chemical and biological process/systems engineering, Processes launched the second Travel Awards for Post-doctoral Fellows and Ph.D. Students. We received a large number of highly meritorious applications from all over the world. On behalf of the Editors of Processes, we are pleased to announce the winners of Processes Travel Awards for 2019.

The awards were granted to Dr. Pratham Arora shown, in Figure 1A, a postdoctoral fellow at the Georgia Institute of Technology, USA, and Ms. Grazia Leonzio, shown in Figure 1B, a Ph.D. student at the University of L'Aquila, Italy. The awards consist of 800 Swiss Francs each to support attendance at an international conference in 2019.

One award supports Dr. Arora's travel to present his research at the Foundations of Computer-Aided Process Design (FOCAPD 2019) in Copper Mountain, USA, for his work "Hydrothermal liquifaction of algae for bio-crude production: Effects of $\mathrm{CO}_{2}$ sourcing on economics and LCA." The second award supports Ms. Leonzio to attend the 29th European Symposium on Computer-Aided Process Engineering (ESCAPE-29) in Eindhoven, The Netherlands. Her presentation is titled "Innovative application of statistical analysis for the optimization of $\mathrm{CO}_{2}$ absorption from flue gas with ionic liquid".

Dr. Arora is a post-doctoral researcher at the Georgia Institute of Technology, working with Prof. Valerie Thomas, and with Prof. Matthew Realff on the modeling of algal processes for the production of biofuel and bioproducts. Dr. Arora has been at Georgia Tech since August 2018; prior to this he was an Associate Fellow at The Energy and Resources Institute (TERI) in New Delhi. Dr. Arora completed his Ph.D. in 2016 at IIT Bombay and Monash University. His Ph.D. work showed the advantages of process modeling and simulation at multiple scales of analysis and that has been published several high-quality journals. We selected Dr. Arora for his excellence in chemical process modeling and environmental life cycle assessment, with strength in biomass processes.

Ms. Leonzio earned a master degree in chemical engineering at the University of L'Aquila in 2013, under the supervision of Prof. Francesco Veglio. From May 2017, she was a Ph.D. candidate from L'Aquila University under the supervision of Prof. Pier Ugo Foscolo and Prof. Edwin Zondervan. 
She works on the modeling and process simulation of chemical processes, renewable energy, carbon dioxide capture and utilization, storage supply chains, wastewater treatment, methanol production, and life cycle assessment analysis. Ms. Leonzio's strong record of publications and conference participation demonstrate her future promise, and so we chose her for participation in the ESCAPE-29 conference.

The Editors and Editorial Board members of Processes congratulate Dr. Pratham Arora and Ms. Grazia Leonzio for winning the 2019 Processes Travel Awards and we are grateful to MDPI for their generous support of the award this year and in the future.

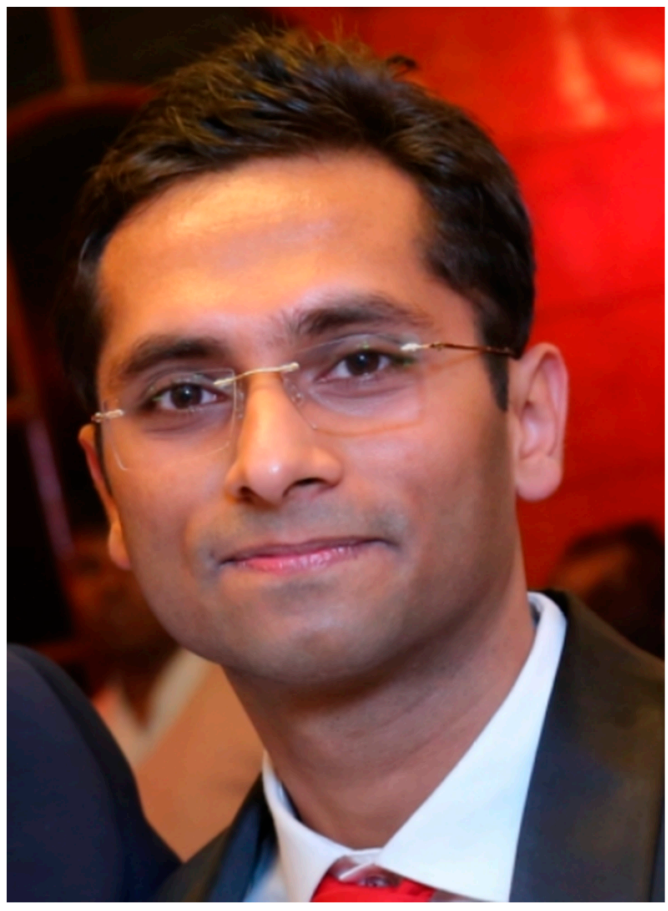

(A). Dr. Pratham Arora

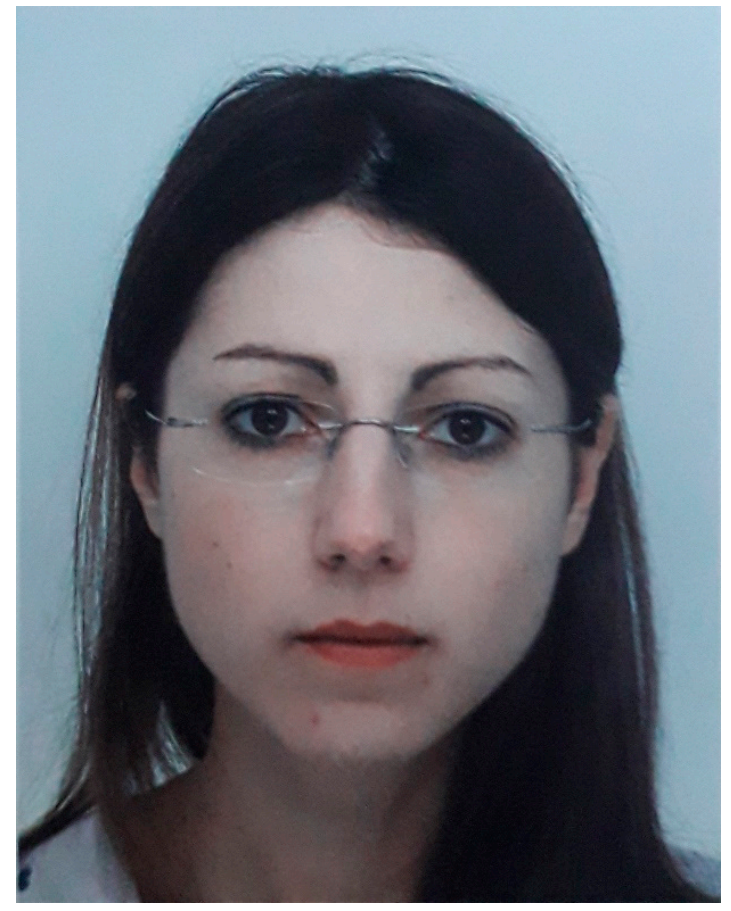

(B) Ms. Grazia Leonzio

Figure 1. The winners of 2019 Processes Travel Awards. (A). Dr. Pratham Arora, (B) Ms. Grazia Leonzio.

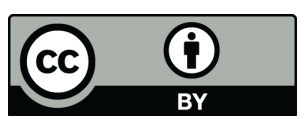

(c) 2019 by the authors. Licensee MDPI, Basel, Switzerland. This article is an open access article distributed under the terms and conditions of the Creative Commons Attribution (CC BY) license (http:/ / creativecommons.org/licenses/by/4.0/). 